\title{
Non-Linear Soil Amplification Identified Empirically from Strong Earthquake Ground Motions
}

\author{
Makoto Kamiyama \\ Department of Civil Engineering, Tohoku Institute of Technology, \\ Taihaku-ku, Sendai 982, Japan
}

\begin{abstract}
Strong earthquake ground motions are influenced remarkably by local soil conditions. Though various factors of local soil conditions contribute to the effect, the effect owing mainly to the non-linear stress-strain relationship of surface soils is discussed in this paper with the aid of statistical analyses. An empirical regression model is presented first to obtain separately the effects due to seismic source, propagation path of waves and local site conditions from strong-motion spectra observed at the ground surface. The model is extended so as to derive soil amplification due to the material non-linearity of surface soils using the proportionality of soil strain to particle velocity and to lead to site-specific soil amplification dependent on the motion level which is called "non-linear soil amplification" in this paper. The extended regression model is applied to 228 strong-motion earthquake records observed at 26 sites in Japan. The non-linear soil amplifications identified by the regression analysis show quite site-dependent and period-dependent characteristics. Although being derived purely based on a statistical technique, the non-linear soil amplifications have a compatible relation with the physical response function resulting from the $S$-wave theory. The comparison between the non-linear soil amplification and their corresponding soil profiles reveals that the non-linearity of local site response is well correlated with the softness and formation of soils, particularly, with the $N$ value distribution at each observation site.
\end{abstract}

\section{Introduction}

As many efforts have been made in the past years, it is nowadays established that earthquake ground motions result mainly from three factors: i.e., seismic source, propagation path of waves and local soil layer conditions (Aki, 1988a). Of the three factors, the third one may play an important role in the short-period range which most engineering structures are concerned with (Aki, 1988b). For example, experiences from a large number of earthquakes in the past have taught us that the areas of severe damage are highly localized and the degrees of damage to structures vary widely over short distances (Okamoto, 1984). Such distinguished aspects of damage show typically that local soil conditions take a deterministic part in causing earthquake damages. Thus the effects due to local soil conditions have become an important subject, particularly, to

Received November 20, 1990; Accepted June 30, 1991 
engineers and the term "soil amplification" has been coined to describe the effects caused by the filtering of earthquake waves through local soil layers (Gazetas et al., 1990).

There may be several sub-factors related to such soil amplification; for example: rigidity, density and viscosity of surface soils, topographical irregularities on and under the ground surface, non-linear relations between strain and stress of soil materials, and so on. The influences pertinent to rigidity, density and viscosity of surface soils have been made clear relatively well by using the flat layered model (Kanai, 1952). In addition, the topographical effects have also attracted engineers' interests through some experiences of earthquake damage such as the 1985 Michoacan earthquake, and many efficient numerical methods for attacking the problem have been presented showing that the topographical effects of soil layers can bring on highly localized amplifications (Sánchez-Sesma, 1987). In comparison with these sub-factors, the effect due to the non-linearity of soil materials has still unclear points, in particular, for strong ground motions because it tends to be covered up by the effects due to the above sub-factors during strong motions. Needless to cite results of dynamic soil test conducted in laboratories and fields, however, soft soil demonstrates remarkable material non-linearity for large strains in response to strong motions (Hardin and Drnevich, 1973). Therefore, it would be possible that such non-linearity plays a significant role in strong-motion response of soft soil layers. Since many large cities in Japan are located on plains composed of soft soils, it is important to clarify the non-linearity effects of soft soils for the purpose of establishing seismic vulnerability assessment in Japan. Such importance is particularly emphasized in applying the Hartzell method to predict strong ground motions (Hartzell, 1978). As is well known, the Hartzell method in which earthquake records obtained during small earthquakes are used as a kind of Green's function for estimating strong motions of a large target earthquake requires the same response of the surface soils for the small and large earthquakes. When the material non-linearity of the surface soils is significant, the method is not straightforwardly applicable because of the different responses of the local soil layers between small and large earthquakes, and some modification would be necessary to apply the method. This shows that the presence of non-linearity effect due to local soils is a key factor to make the Hartzell method a success.

The first objective of this paper is to present a simplified method for identifying amplification characteristics brought about by the material non-linearity of local soil layers from strong earthquake ground motions. The second is to examine how the soil amplifications derived by the method are varied according to the ground motion level, i.e., maximum particle velocity at the ground surface. The third purpose is to compare them with the local soil conditions and to give information on possible non-linear behavior of local soils associated with their softness.

In general, evidence of non-linear soil response during strong earthquake shakings requires records simultaneously obtained on the ground surface and at depth in a borehole. In contrast to such a general technique, this paper deals with a method for determining the non-linear response characteristics only from the ground surface records. In order to do so, a regression model of strong-motion spectra presented by Kamiyama and Yanagisawa (1986) and Kamiyama (1987) is extended in this paper. This extended regression model not only makes it possible to separate the source spectra, path spectra 
and site spectra which are respectively peculiar to seismic source, propagation path of waves and local site conditions, but also gives an insight into the non-linear response characteristics of local soil layers varied in accordance with the shaking level. Finally the non-linear response characteristics identified empirically by the model are discussed in comparison with the soil log profiles of each observation site.

\section{Examples of Non-Linear Response Apparent in Observed Strong-Motion Spectra}

Figure 1 (a), (b), (c), and (d) show examples of strong-motion spectra. They were obtained at four representative sites of the strong-motion observation network administered by the reports of the Port and Harbour Research Institute (1969-1983) under various earthquake conditions. It is seen in the figures that strong-motion spectra are dependent not only on earthquake factors but on each site condition as well. One part of the objective of this paper is to extract the site-dependent amplification factors by dealing statistically with the strong-motion spectra observed at the ground surface. We can also see in Fig. 1 that the site-dependency included in the observed spectra varies from site to site perhaps relying on each site condition, even though it is overlapped by the other factors like source-dependency. For instance, the sites such as Shiogama and Hososhima give rather conceivable variation of the site-dependency with motion levels demonstrating a clear increase of predominant periods, whereas the other sites like Kushiro and Miyako indicate relatively consistent site-dependency irrespective of motion levels. This is considered to be an example that amplification factors due to local soil conditions can vary with motion level. In this paper we attempt to obtain soil amplification factors dependent on motion level.

Theoretically speaking, as far as the soil materials have linear stress-strain relationship, their amplification factors are determined uniquely as a frequency response function on the basis of the soil layer conditions. So we might be able to derive the soil amplification as a parameter unique to a site from the observed strong-motion spectra on the condition that the soils show little material non-linearity. In case of some conspicuous non-linearity of soil materials, however, we can no longer expect amplification factors peculiar to only site conditions. They may depend markedly on magnitude of time-varying strain or something induced in soils and have some non-stationary characteristics. Though one needs a method faithful to such complicated non-linearity of soil material, it is almost impossible to extract soil amplification applicable to non-stationary behavior of soil materials merely from some limited strongmotion spectra observed at the ground surface. Accordingly, a simplified definition of soil amplification resulting from the material non-linearity of soils is attempted in this paper so as to derive easily from only the strong-motion spectra at the ground surface. That is, in reference to the so-called "equivalent linear approximation" used in earthquake response analyses (Erdik, 1987), we herein introduce a concept of soil amplification in which the amplification factor depends on the motion level. We hereafter call such soil amplification "non-linear soil amplification."

Vol. 40, No. 1, 1992 


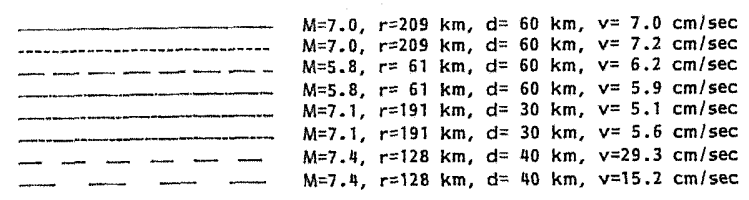

(a)

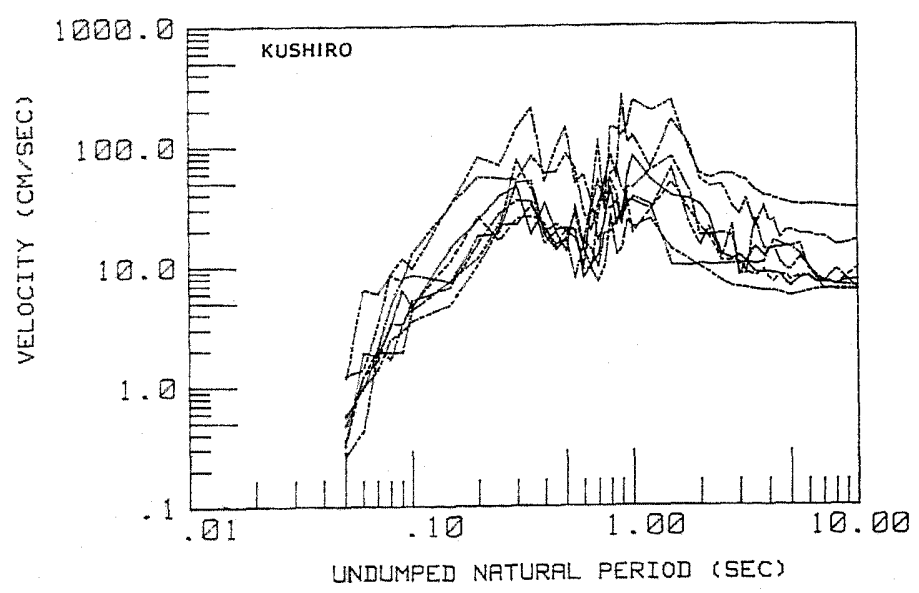

(b)

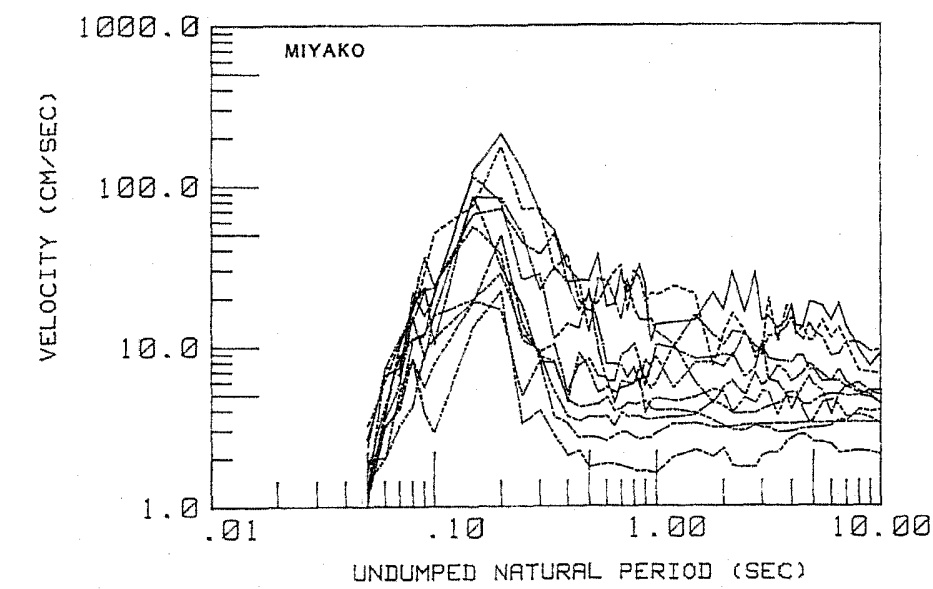

Fig. 1. (a) Observed spectra at the Kushiro site. The spectra are expressed by velocity response spectra with no damping. $M, r$, and $d$ mean earthquake magnitude, epicentral distance and focal depth, respectively. $v$ is maximum particle velocity numerically obtained from the observed accelerogram. 
(c)
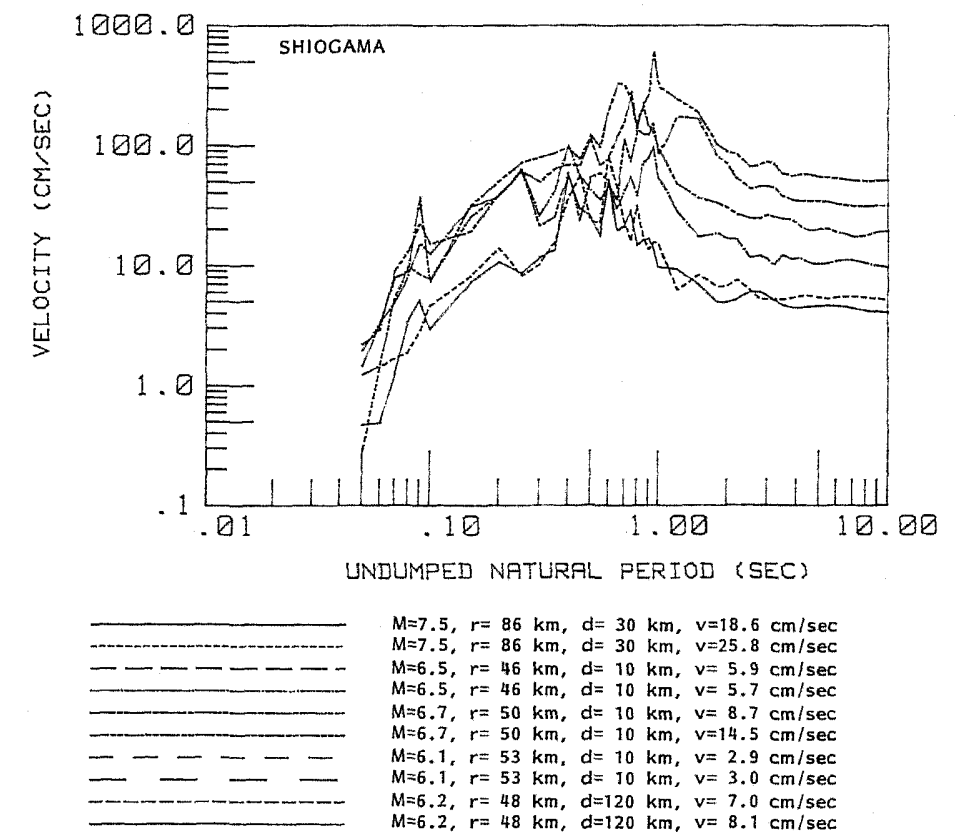

(d)

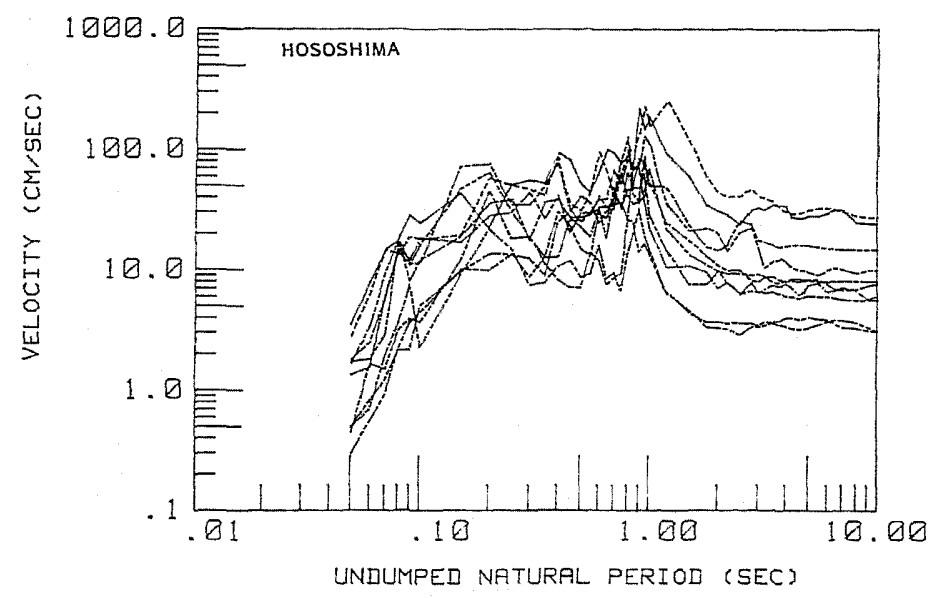

(b) Observed spectra at the Miyako site. The spectrum expression and symbols are the same as in (a). (c) Observed spectra at the Shiogama site. The spectrum expression and symbols are the same as in (a). (d) Observed spectra at the Hososhima site. The spectrum expression and symbols are the same as in (a).

Vol. 40, No. 1, 1992 


\section{Regression Model of Strong-Motion Spectra to Identify Non-Linear Amplification}

As stated above, earthquake ground motions are influenced by the three main factors of seismic source, propagation path of waves and local soil conditions. Combinations of such factors were already shown in Fig. 1. Kamiyama and Yanagisawa (1986) and Kamiyama (1987) presented a statistical method by which the effects due to the three factors can be easily separated from strong ground motion spectra provided that they have been obtained at many observation sites under various earthquake factors. The method was based on a regression analysis of spectra in which amplification factors due to local soil conditions of each observation site were made clear with the aid of the concept of the dummy variables. The regression model was given by (Kamiyama, 1987)

$\log _{10} V(T)=a(T) M^{2}+b(T) M+c(T) \log _{10}(\Delta+30)+d(T) D+e(T)+\sum_{i=1}^{N-1} A_{i}(T) S_{i}$,

where $V(T)$ denotes spectra of ground motions; $M$, earthquake magnitude; $\Delta$, epicentral distance $(\mathrm{km}) ; D$, focal depth $(\mathrm{km}) ; N$, total number of observation sites; $S_{i}$, dummy variables; $a(T), b(T), c(T), d(T) e(T)$, and $A_{i}(T)$, regression coefficients; and $T$, period.

The backgrounds regarding Eq. (1) were thoroughly described in Kamiyama and Yanagisawa (1986) and Kamiyama (1987). In summary, Eq. (1) models earthquake ground motion spectra resulting from earthquake magnitude, focal depth, epicentral distance and dummy variables which simply express, respectively, the effects due to seismic source, propagation path of waves and local site conditions, by utilizing and expanding the definition of earthquake magnitude. According to Eq. (1), the amplification factor of spectra $A M P_{i}(T)$, which is physically equivalent to the theoretical frequency response function, specific to the $i$-th site against a reference site is determined as follows (Kamiyama and Yanagisawa, 1986):

$$
A M P_{i}(T)=2 \cdot 10^{A_{i}(T)}
$$

Even though it is quite effective to obtain simply the effects due to seismic source, propagation path of waves and local site conditions, Eq. (1) has such an insufficient point that amplification factors are determined as a peculiar parameter to each observation site in disregard of their corresponding motion levels, as definitely shown in Eq. (2). Namely, Eq. (1) implicitly assumes that there exists no difference in the amplification factors between strong motions and weak ones. Judging from the examples of spectra in Fig. 1, however, it would be natural to consider that amplification factors can undergo a change in response to earthquake motion levels. As explained in the preceding section, some sites exemplified in Fig. 1 show some variation of amplification factors with motion levels. Of course, such variation may reflect not only the material non-linearity of soils but also other factors such as the difference of wave propagation mechanism including the effect of topographical irregularities. But, since the effects caused by the latter factors make their appearance regardless of motion levels, the variation found in Fig. 1 would be brought about principally by the former effect. In this paper, therefore, we focus our attention on the variation of amplification factors 
due to the material non-linearity and derive the non-linear soil amplification by extending Eq. (1).

As known from various dynamic soil tests in laboratories and fields (Hardin and Drnevich, 1973), soil strain induced during earthquakes is the most important parameter controlling non-linear behavior of ground motions. In spite of such importance, there has been almost no observation of soil strain because of the technical difficulty, and it is thus impossible to introduce such parameter into the regression model of Eq. (1). On the other hand, it is shown from the wave theory having one-dimensional propagation that strain is proportional to its corresponding particle velocity (Kolsky, 1963). Referring to the theory, we assume in this study that the variations of non-linear soil amplification are controlled mainly by the maximum particle velocity at the ground surface which is relatively easily obtained by numerical calculation from the observed surface accelerograms or by direct observation, and introduce it into Eq. (1) as a replacement of the strain. When introducing the maximum particle velocity at the ground surface into Eq. (1), it is necessary to treat it as a site-dependent variable because it varies remarkably depending on local site conditions. In this point, Eq. (1) already gives us a clue for such treatment, that is, the concept of the dummy variable is also applicable to the site-dependency of maximum particle velocity. This idea leads to building the following regression model by adding new terms, which include the dummy variables as well as the maximum particle velocity at the ground surface, into Eq. (1):

$$
\begin{aligned}
\log _{10} V(T)= & a(T) M^{2}+b(T) M+c(T) \log _{10}(\Delta+30) \\
& +d(T) D+e(T)+\sum_{i=1}^{N-1} A_{i}(T) S_{i}+\sum_{j=1}^{N} B_{j}(T) v S_{j},
\end{aligned}
$$

where $v$, maximum particle velocity at the ground surface $(\mathrm{cm} / \mathrm{s}) ; S_{j}$, dummy variables; and $B_{j}(T)$, regression coefficients.

In Eq. (3), the number of the term $B_{j}(T) v S_{j}$ is given by $N$ equal to the total number of observation sites, while the one for the term $A_{i}(T) S_{i}$ by $N-1$. The total number $N-1$ for the term $A_{i}(T) S_{i}$ was given for the reason of obtaining unique solutions of $A_{i}(T)$, as stated fully in Kamiyama and Yanagisawa (1986). As against the term $A_{i}(T) S_{i}$, we can obtain unique solutions of $B_{j}(T)$ even for $N$ in the case of the term $B_{j}(T) v S_{j}$ because an explicit variable $v$ is multiplied in it.

Equation (3) is a multiple regression model consisting of the independent variables $M, D, \Delta$, and $v$ as well as the dummy variables. Among these independent variables, the variable $v$ is a little different from the others in the point of independent degree, because it strongly relies on $M, \Delta$, and $D$ in addition to being site-dependent. This means that a similar regression expression to Eq. (1) can be satisfied about the variable $v$, namely,

$$
\log _{10} v=a^{\prime} M^{2}+b^{\prime} M+c^{\prime} \log _{10}(\Delta+30)+d^{\prime} D+e^{\prime}+\sum_{i=1}^{N-1} A_{i}^{\prime} S_{i},
$$

where $v$, maximum particle velocity at the ground surface; $M$, earthquake magnitude; $\Delta$, epicentral distance $(\mathrm{km}) ; D$, focal depth $(\mathrm{km}) ; S_{i}$, dummy variable; and $a^{\prime}, b^{\prime}, c^{\prime}, d^{\prime}$, $e^{\prime}$, and $A_{i}^{\prime}$, regression coefficients.

Vol. 40, No. 1, 1992 
As seen by substituting Eq. (4) into Eq. (3), Eq. (3) can be said to be a kind of highly complicated multiple regression model composed only of the independent variables $M, \Delta$, and $D$. Although Eq. (3) can be said so, it is required in this paper to make the variable $v$ explicit in Eq. (3) so that the non-linear soil amplification can be derived by a function of the motion level, that is, the maximum particle velocity $v$.

Similarly to Eq. (2), the amplification factor of the maximum particle velocity at the $i$-th site against a reference site is obtained as $10^{A_{i}^{\prime}}$ from Eq. (4). In other words, when the maximum particle velocity at a reference site during an earthquake is given by $v$, the maximum particle velocity $v_{i}$ at the $i$-th site for the same earthquake condition is expected statistically to become

$$
v_{i}=10^{A_{i}^{\prime}} \cdot v \text {. }
$$

Using Eqs. (3) to (5), we finally obtain the amplification factor of spectra at the $i$-th site $A M P_{i}(T)$, as follows, which is dependent on site as well as on the maximum velocity $v$ at a reference site:

$$
A M P_{i}(T)=2 \cdot 10^{A_{i}(T)+B_{i}(T) v \cdot 10 A_{i}^{\prime}} / 10^{B_{B}(T) \cdot v},
$$

where $B_{B}(T)$ corresponds to the $B_{i}(T)$ for a reference site.

Although the reference site stated above can be picked up arbitrarily from any of the observation sites, the most desirable is to select a site where there exists outcrop hard enough to constitute the seismic bed rock for the other sites, as described in Kamiyama and Yanagisawa (1986). Under such selection of reference site, the variable $v$ in Eq. (6) is interpreted equivalently as the maximum particle velocity on the seismic bed rock which is virtually underlain at each observation site as well as being associated with the outcrop rock of the reference site. Thus, Eq. (6) becomes equivalent physically to the amplification factors varying with the maximum particle velocity given on the virtual underlying seismic bed rock of each site, namely, it finally follows that we can obtain our target "non-linear soil amplification" through Eq. (6).

\section{Strong-Motion Records for the Regression Analyses}

In order to apply the models of Eqs. (3) and (4) to our regression analyses, we employed 228 horizontal strong-motion accelerograms obtained in Japan having maximum acceleration greater than 20 gal. The records are listed in Table 1 of Kamiyama and Yanagisawa (1986), together with earthquake magnitude, focal depth, epicentral distance and maximum acceleration. As shown in the table, these redords were observed at the ground surface of 26 sites in all during 68 various types of earthquakes. The origins of the earthquakes are indicated in Fig. 2 together with the observation sites. The records are from earthquakes with the Japan Meteorological Agency magnitude $M_{\mathrm{J}}$ ranging from 4.1 to 7.9 , the focal depth from 0 to $130 \mathrm{~km}$ and the epicentral distance from 10 to $310 \mathrm{~km}$. Their histograms are shown, respectively, in Figs. 3, 4, and 5, and the distribution of $M_{\mathrm{J}}$ is plotted in Fig. 6 together with the data of epicentral distance. Figures 3 to 6 indicate that there are few large earthquakes in a near distance in our data set.

We computed velocity response spectra with no damping from the strong-motion 
- observation SITE

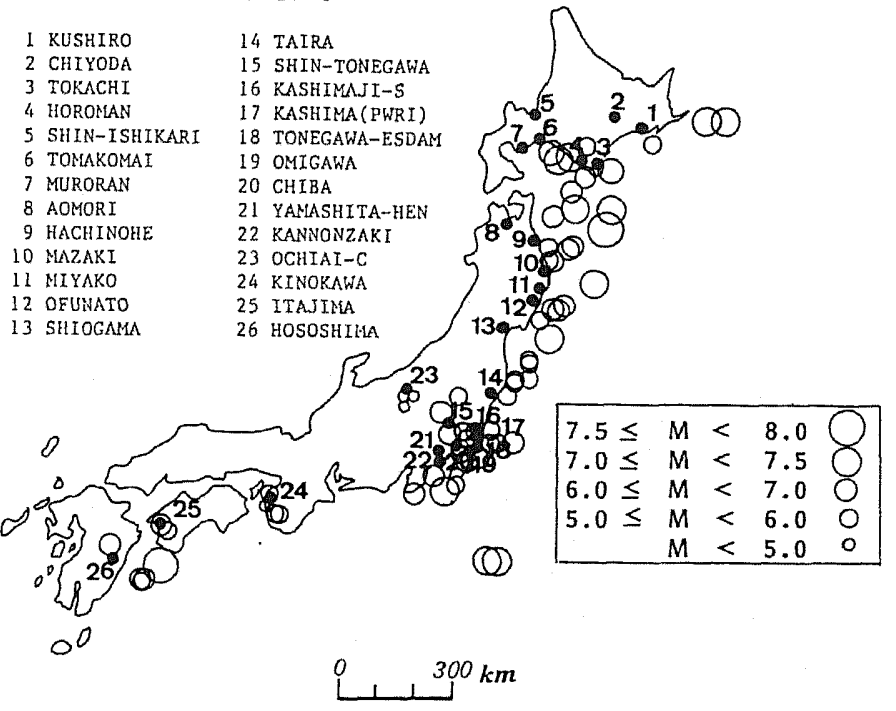

Fig. 2. Earthquake origins and observation sites for the strong-motion records used in the present study.

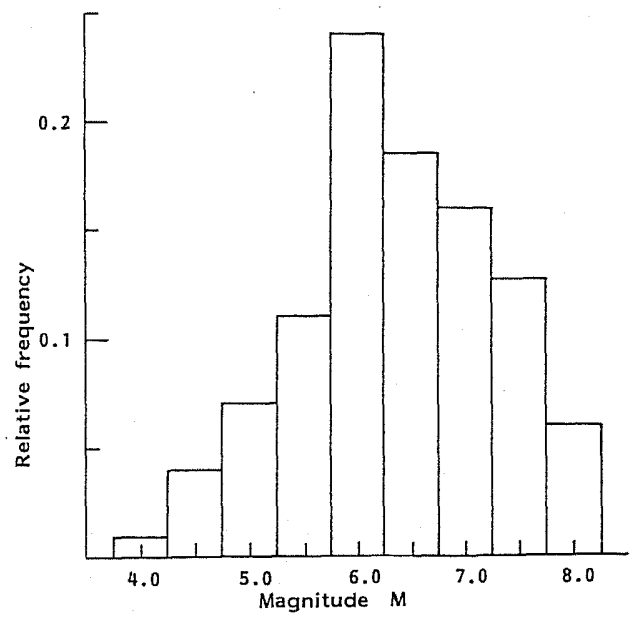

Fig. 3. Histogram of earthquake magnitude.

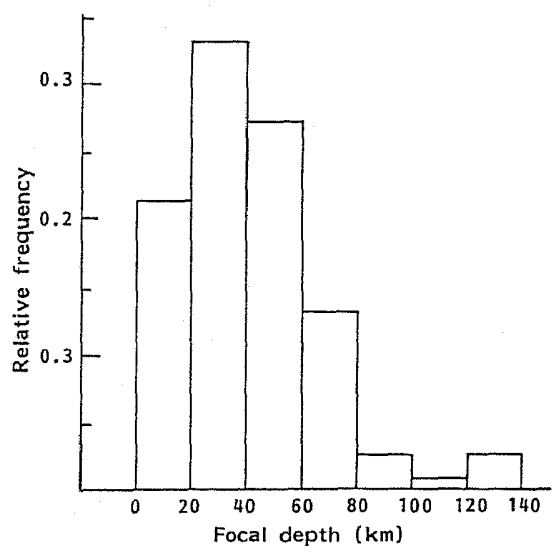

Fig. 4. Histogram of focal depth.

records described above and used them as $V(T)$ in Eq. (3). The reason for using such velocity response spectra is that they are nearly equal to Fourier spectra besides being useful from an engineering point of view, as already explained in Kamiyama (1987). On the other hand, the maximum particle velocity $v$ employed as an independent variable in Eq. (3) was obtained numerically from the observed strong-motion accelerograms. The numerical estimation was based on the method by Iai et al. (1978) which obtains

Vol. 40 , No. 1,1992 


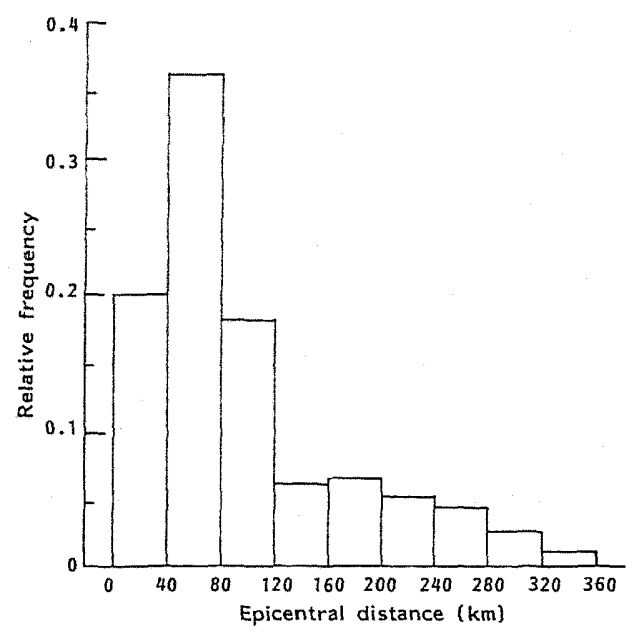

Fig. 5. Histogram of epicentral distance.

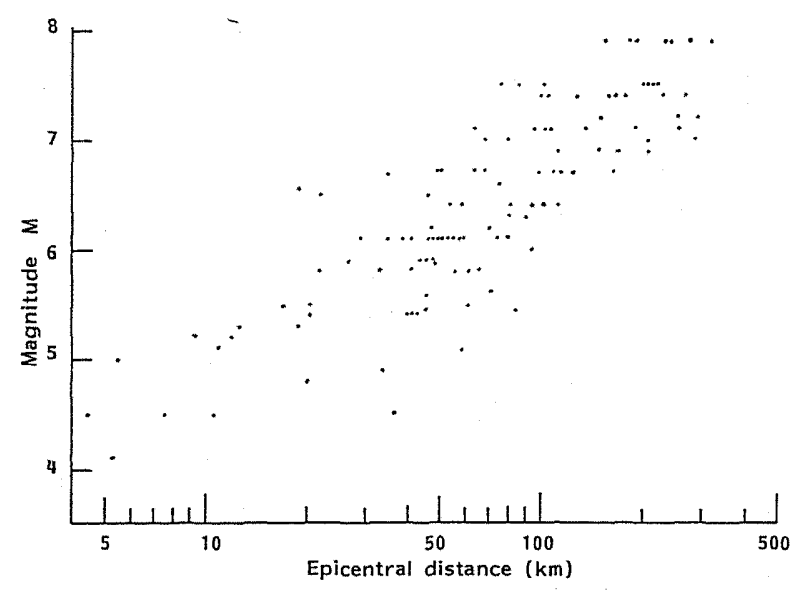

Fig. 6. Distribution of earthquake magnitude and epicentral distance.

velocity record from observed accelerogram by performing a numerical integration with application of a high an low pass filters. An example of the numerically obtained velocity record is shown in Fig. 7 together with its original accelerogram. The maximum particle velocity was obtained as a maximum value of these numerical velocity records and was applied to Eqs. (3) and (4). The histogram for such maximum particle velocities is drawn in Fig. 8.

\section{Regression Analyses for the Maximum Particle Velocities and Velocity Response Spectra}

Applying the models of Eqs. (3) and (4) to the maximum particle velocities and 

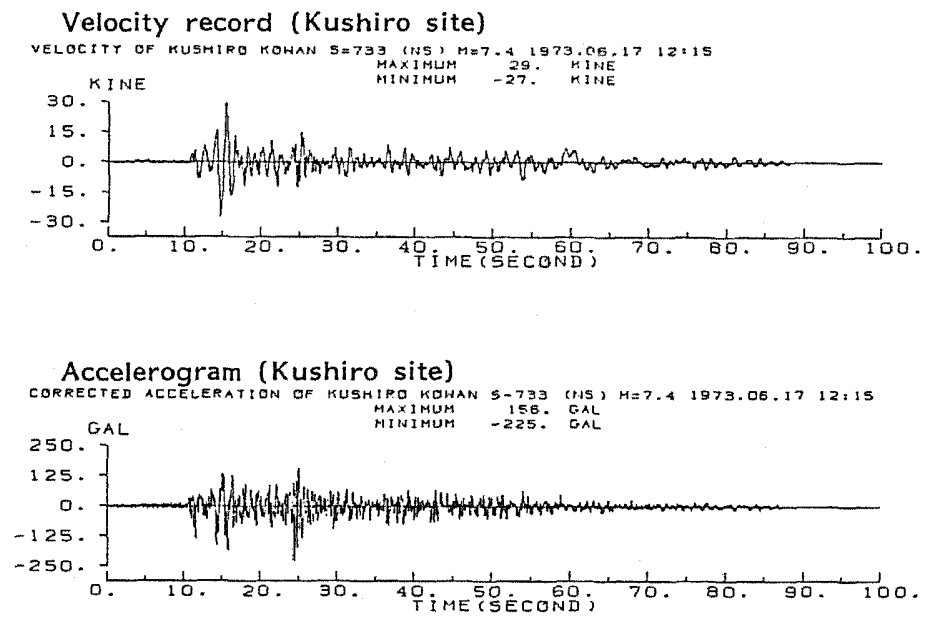

Fig. 7. An example of the numerically obtained velocity record and its original accelerogram.

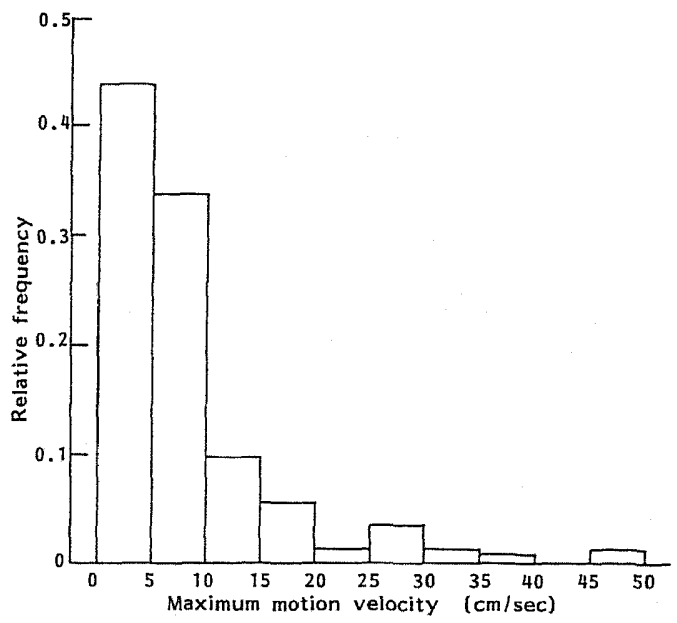

Fig. 8. Histogram of the maximum particle velocity.

the velocity response spectra with no damping, respectively, we carried out the multiple regression analyses by the least squares technique. In the analyses, it is needed, as stated in the foregoing, to assign one site as the reference site so as to estimate the non-linear soil amplification with some physical implication. The Ofunato site labeled 12 in Fig. 2 was herein selected as the reference site for the same reason described in Kamiyama (1987). According to the selection, it follows that the virtual seismic bed rock here is a deposit equivalent to Ofunato's outcrop rock whose shear wave velocity is supposed to be $1-2 \mathrm{~km} / \mathrm{s}$.

Vol. 40, No. 1, 1992 
Table 1. Results of regression coefficient $A_{i}^{\prime}$ for each observation site obtained from the analysis of the maximum particle velocity. The results are given by $10^{A_{i}}$ so as to express amplification factor of the maximum particle velocity.

\begin{tabular}{ll|ll}
\hline \multicolumn{1}{c|}{ Site } & $10^{A_{i}^{\prime}}$ & Site & $10^{f_{i}^{\prime}}$ \\
\hline Kushiro & 1.61 & Shin-tonegawa & 1.32 \\
Chiyoda & 1.15 & Kashimaji-s & 1.64 \\
Tokachi & 0.75 & Kashima (pwri) & 1.90 \\
Horoman & 0.55 & Tonegawa-esdam & 2.28 \\
Shin-ishikari & 2.21 & Omigawa & 2.09 \\
Tomakomai & 0.67 & Chiba & 1.14 \\
Muroran & 1.22 & Yamashita-hen & 1.05 \\
Aomori & 1.34 & Kannonzaki & 0.85 \\
Hachinohe & 1.01 & Ochiai-c & 1.92 \\
Mazaki & 0.91 & Kinokawa & 0.77 \\
Miyako & 0.76 & Itajima & 1.87 \\
Shiogama & 2.50 & Hososhima & 1.36 \\
Taira & 1.24 & & \\
\hline
\end{tabular}

\subsection{Analysis results for the maximum particle velocities}

The application of Eq. (4) to the maximum particle velocities resulted in the following regression expression:

$$
\log _{10} v=0.0864 M^{2}-0.732 M-0.451 \log _{10}(\Delta+30)+0.001 D+2.65+\sum_{i=1}^{N-1} A_{i}^{\prime} S_{i},
$$

in which $A_{i}^{\prime}(i=1-25)$ are given to each observation site except for the reference site Ofunato as shown in Table 1. Also the multiple correlation coefficient and standard deviation for the expression of Eq. (7) were obtained, respectively, to be 0.78 and 0.20 . Since the main purpose of this paper is not to investigate the empirical scaling manner of maximum particle velocity but to derive the variation of soil amplification in response to motion level, detailed examination of the results is beyond the scope of this study. Even with a cursory examination, however, Eq. (7) and Table 1 reveal some interesting aspects related to scaling of maximum velocity; for example, one can see in Table 1 that maximum velocity varies remarkably from site to site and has a possibility of being amplified 2-3 times depending on local site conditions for the same source and path conditions.

\subsection{Analysis results for the response spectra with no damping}

The regression coefficients analyzed according to Eq. (3) are given as a function of period. The obtained regression coefficients $a(T), b(T), c(T), d(T)$, and $e(T)$ are shown in Fig. 9. Also the results of the regression coefficients $A_{i}(T)$ and $B_{i}(T)$ which differ from site to site are put into shape of a period function for 6 representative observation sites, as shown in Fig. 10 (a) and (b). It is seen in Figs. 9 and 10 that the regression coefficients here depend strongly on period and such site-dependent coefficients as $A_{i}(T)$ and $B_{i}(T)$ vary considerably depending on local site conditions. Meanwhile, the multiple correlation coefficients and standard deviations obtained using 


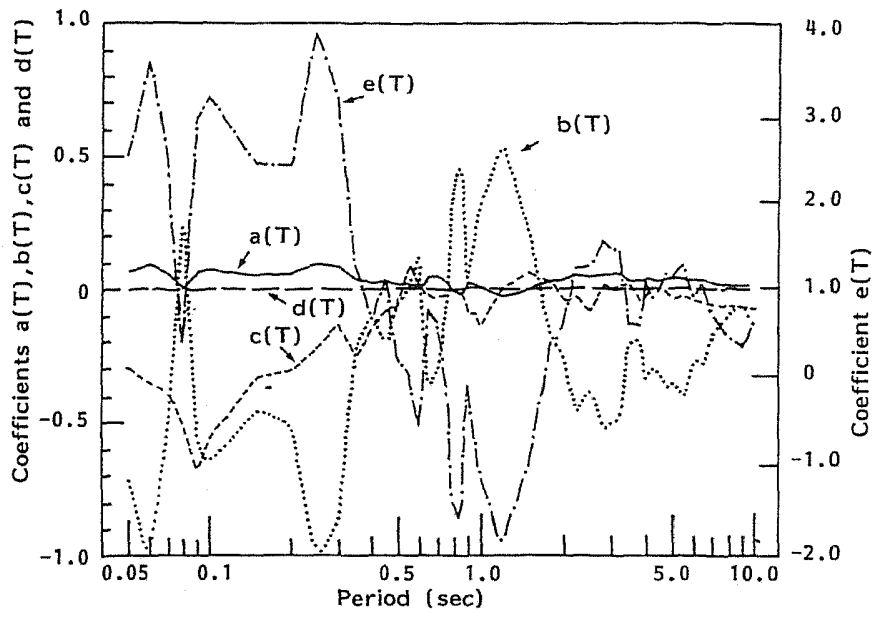

Fig. 9. Results of the regression coefficients $a(T), b(T), c(T), d(T)$, and $e(T)$.

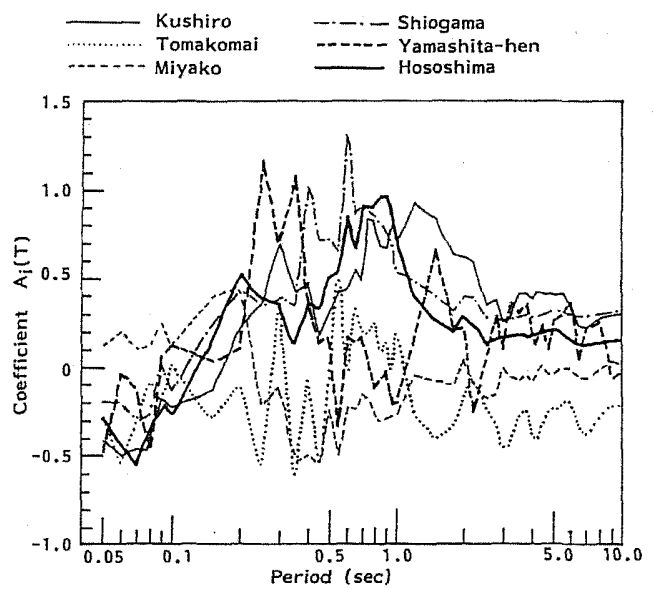

(a)

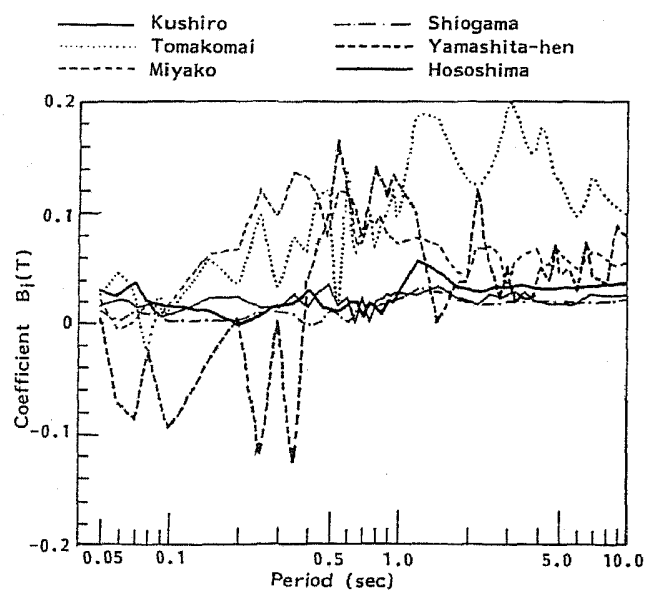

(b)

Fig. 10. (a) Results of the regression coefficient $A_{i}(T)$ for the representative sites.

(b) Results of the regression coefficient $B_{i}(T)$ for the representative sites.

Eq. (3) are shown for representative periods in Table 2 in comparison with the results of Eq. (1). We can see in Table 2, as expected, that Eq. (3) gives far more reasonable results than Eq. (1).

\section{Non-Linear Soil Amplification Identified from the Regression Analyses}

Using the regression coefficients obtained above makes it possible to scale strong-motion spectra in terms of earthquake magnitude $M$, epicentral distance $\Delta$, focal 
Table 2. Results of the multiple correlation coefficients and standard deviations obtained by the analyses of Eqs. (1) and (3).

\begin{tabular}{ccccc} 
& \multicolumn{2}{c}{ Model Eq. (1) } & \multicolumn{2}{c}{ Model Eq. (3) } \\
$\begin{array}{c}\text { Period } \\
(\mathrm{s})\end{array}$ & $\begin{array}{c}\text { Standard } \\
\text { deviation }\end{array}$ & $\begin{array}{c}\text { Multiple correlation } \\
\text { coefficient }\end{array}$ & $\begin{array}{c}\text { Standard } \\
\text { deviation }\end{array}$ & $\begin{array}{c}\text { Multiple correlation } \\
\text { coefficient }\end{array}$ \\
\hline 0.10 & 0.242 & 0.794 & 0.231 & 0.841 \\
0.20 & 0.245 & 0.797 & 0.219 & 0.863 \\
0.30 & 0.243 & 0.747 & 0.208 & 0.848 \\
0.50 & 0.245 & 0.825 & 0.197 & 0.906 \\
0.70 & 0.255 & 0.847 & 0.196 & 0.925 \\
1.00 & 0.278 & 0.849 & 0.227 & 0.915 \\
1.50 & 0.261 & 0.848 & 0.195 & 0.930 \\
2.00 & 0.234 & 0.863 & 0.169 & 0.941 \\
3.00 & 0.207 & 0.872 & 0.128 & 0.959 \\
4.00 & 0.199 & 0.860 & 0.125 & 0.955 \\
\hline
\end{tabular}

depth $D$ and local site conditions. In this paper, we are mainly interested in the amplification factors due to local soil conditions, so the scaling of spectra is not examined here. Instead, we focus our attention on the non-linear soil amplification derived from Eq. (6).

As Eq. (6) indicates, one can estimate the non-linear soil amplification of each observation site by the use of the coefficients $A_{i}(T), B_{i}(T), A_{i}^{\prime}$, and $B_{B}(T)$ obtained from the regression analyses and the maximum velocity $v$ given arbitrarily on the virtual seismic bed rock. On account of space consideration, we herein show the non-linear soil amplifications estimated only for the 6 representative sites whose regression coefficients were plotted in Fig. 10. The non-linear soil amplifications for these sites are drawn in Figs. 11 to 16 where they are given so as to be responsive to the variation of maximum velocity on the virtual seismic bed rock. In these figures, the maximum velocities are varied in an identical manner. The maximum velocities of $1,4,8$, and $12 \mathrm{~cm} / \mathrm{s}$ correspond, respectively, to the regressed values for $M=5.0,6.5,7.2$, and 7.5 with $\Delta=80 \mathrm{~km}$ and $D=0 \mathrm{~km}$ according to Eq. (7). One can see from Figs. 11 to 16 that the non-linear soil amplifications statistically obtained here are not only quite specific to each site but remarkably dependent on period as well. It is also shown in these figures that the degree of non-linearity, namely, the dependence of amplification factors on the maximum velocity, is greatly sensitive to site conditions. In other words, it follows from Figs. 11 to 16 that the non-linearity of amplification due to local site conditions varies markedly depending on its soil profile. Therefore, our next interest is to find the relationships between the above non-linear soil amplifications and the corresponding soil profiles. Such relationships will be discussed in the following section. At this stage, the comparison of amplification factors derived from Eq. (3) with the ones from Eq. (1) is also another interest to check the non-linearity of amplification because Eq. (3) includes the non-linear effect while no inclusion of the non-linearity in Eq. (1), as stated in the preceding. One example of such comparison is shown in Fig. 17 for the Shiogama site. It would be pointed out from Fig. 17 that Eq. (1), which 


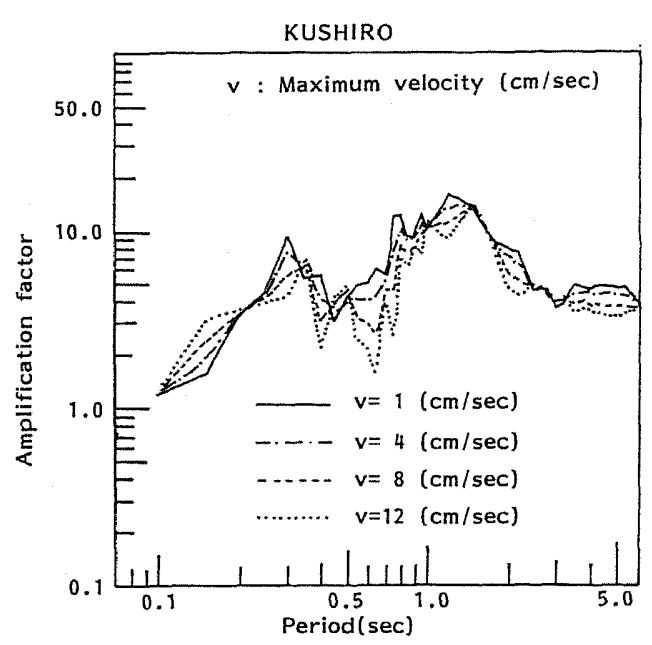

Fig. 11

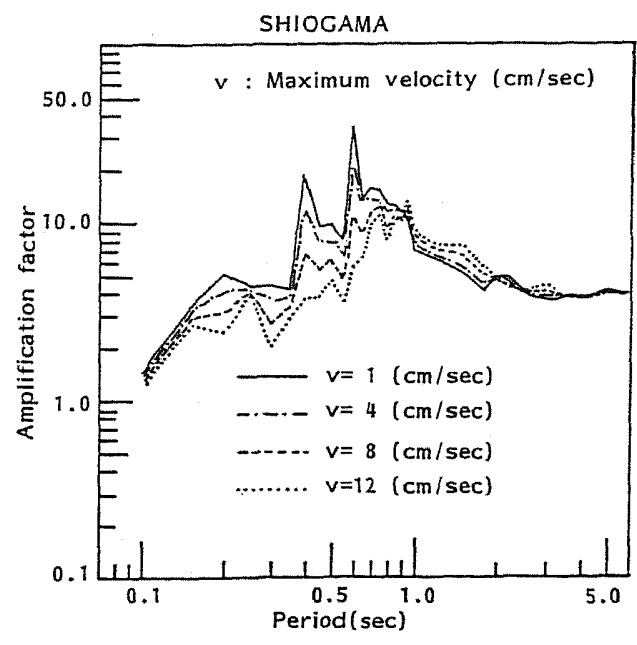

Fig. 12

Fig. 11. Non-linear soil amplification at the Kushiro site. $v$ means the maximum particle velocity on the virtual seismic bed rock.

Fig. 12. Non-linear soil amplification at the Shiogama site. Symbols are the same as in Fig. 11.

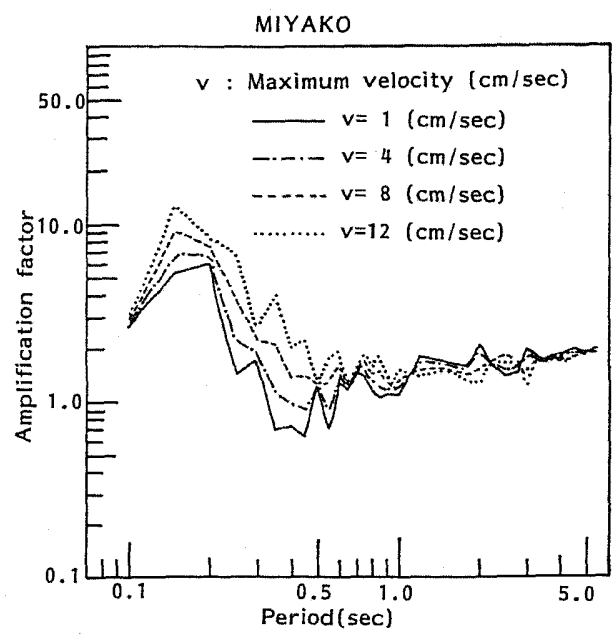

Fig. 13

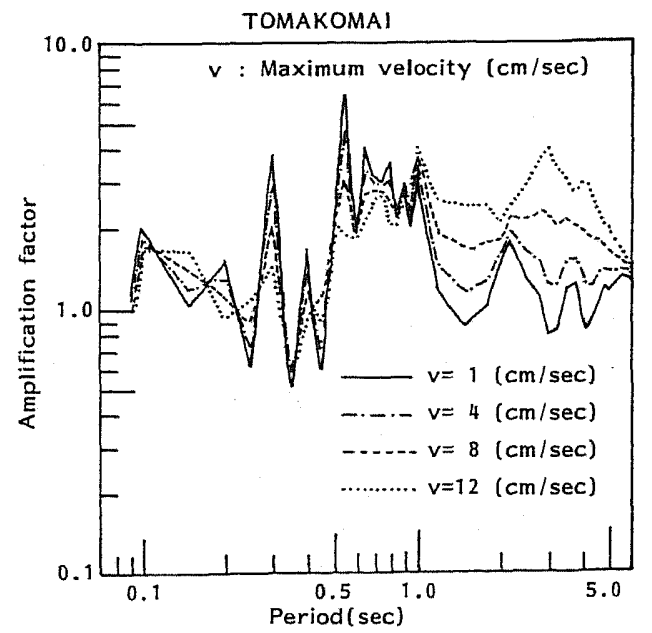

Fig. 14

Fig. 13. Non-linear soil amplification at the Miyako site. Symbols are the same as in Fig. 11.

Fig. 14. Non-linear soil amplification at the Tomakomai site. Symbols are the same as in Fig. 11.

Vol. 40, No. 1, 1992 


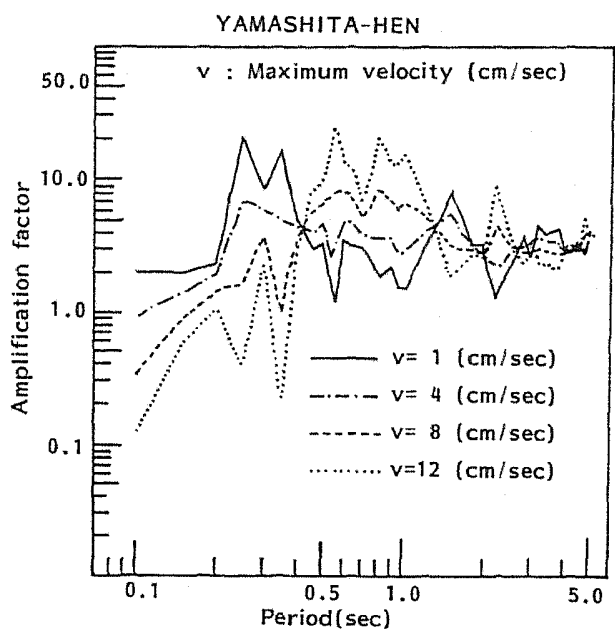

Fig. 15

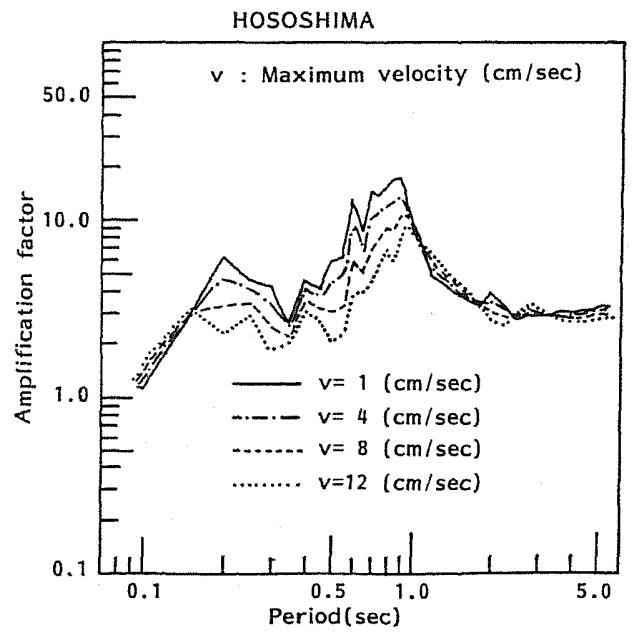

Fig. 16

Fig. 15. Non-linear soir amplification at the Yamashita-hen site. Symbols are the same as in Fig. 11.

Fig. 16. Non-linear soil amplification at the Hososhima site. Symbols are the same as in Fig. 11.

ignores the effects due to the non-linearity, presents a kind of averaged amplification factors against Eq. (3). On the other hand, the non-linear soil amplifications shown in Figs. 11 through 16 contain some statistical errors which are integrated by the standard errors of all the regression coefficients in Eq. (6). Since the integrated form of the statistical errors is complicated and also depends on period and site, a simple expression of the errors is not easy. We herein present one example of the statistical errors due primarily to the standard error of the regression coefficient $B_{i}(T)$ which directly controls the non-linearity of soil amplification. Figure 18 shows an example of the error band of the non-linear amplification factors estimated at the Shiogama site by considering one standard error of the regression coefficient $B_{i}(T)$. We can see in Fig. 18 that the larger maximum velocity gives the wider error band of amplification factors. But, the distinctive variation of amplification factors which will be described in the following section, for example, the phenomenon of the longer predominant period with the larger motion level, is clear even within the error bands. Therefore we discuss the correlations between the non-linear amplification factors and local soil conditions without considering the statistical errors in the following section.

\section{Correlation between the Non-Linear Amplification Factors and the Local Soil Profiles}

The soil profiles at each site of Figs. 11 to 16 are shown, respectively, in Figs. 19 to 24 in order to investigate how the non-linear soil amplification correlates with their local soil conditions. These soil profiles were obtained from the site data compiled by the Port and Harbour Research Institute, Ministry of Transport (Tsuchida, 1967, 1970, 


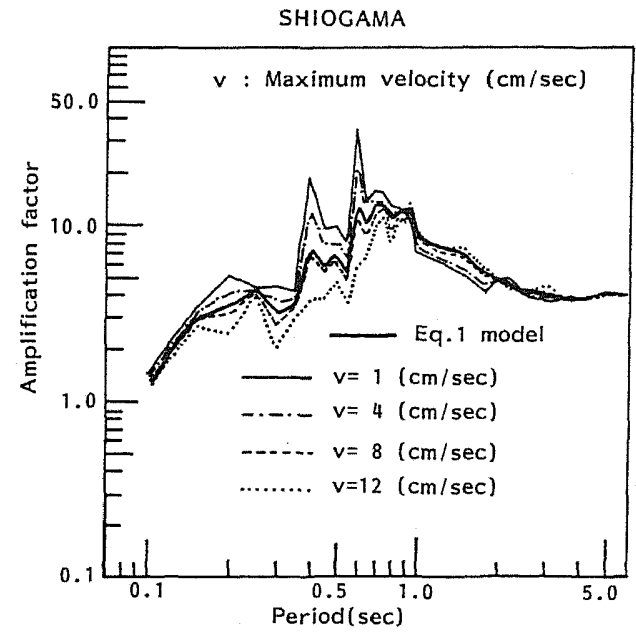

Fig. 17

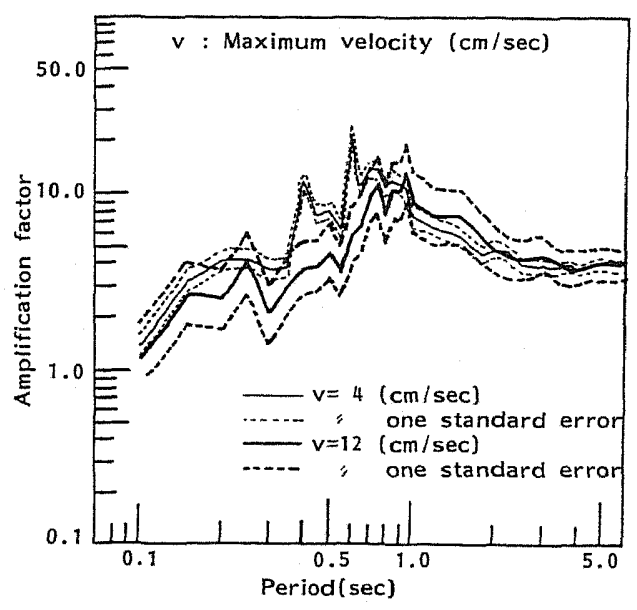

Fig. 18

Fig. 17. Comparison of the non-linear soil amplification obtained by Eq. (3) with the soil amplification by Eq. (1). The soil amplification due to Eq. (1) is given as a parameter peculiar to site whereas the ones by Eq. (3) vary according to the maximum particle velocity. The comparison is shown for the Shiogama site.

Fig. 18. An example of the error band of the non-linear soil amplification at the Shiogama site. The solid lines show the same as in Fig. 12 and the dotted lines mean the errors estimated by considering one standard error of the regression coefficient $B_{i}(T)$.

1973). Referring to the standard penetration test results meeting the Japanese Industrial Standard, i.e., $N$ values plotted in these figures, one can see that each site is rich in variety of softness of soils and has various soil formations. For example, the Shiogama site consists of extremely soft silty soils underlain by a hard rock, whereas rather stiff gravel layers overlying on a rock constitute the Miyako site. Both of the Shiogama and Miyako sites have rock layers at a comparatively shallow depth, particularly, the rock layer of the latter site is found at the shallowest depth among all the sites in Figs. 19 through 24 . The Hososhima site also has several layers changing alternately from soft to hard overlying on a hard rock. Contrary to these three sites, the other sites Kushiro, Tomakomai, and Yamashita-hen have no rock deposits within the depths of boring $\log$, and there seems to be a rock at a greater depth. Concerning the averaged softness of shallow layers less than a depth of about $15 \mathrm{~m}$, the Kushiro and Tomakomai sites appear to have harder layers in comparison with Yamashita-hen. In the case of the Kushiro site, $N$ values are not clear in the layers shallower than about $7 \mathrm{~m}$, but the layers seem to be hard judging from the gravel dominant in them. The characteristic point to the Tomakomai site is that it is formed with a clear low-rigidity layer of sandy loam overlain by rather firm sandy gravel.

A close look at the non-linear soil amplifications in Figs. 11 through 16 and at the soil profiles in Figs. 19 through 24 reveals some interesting correlations between them.

Vol. 40, No. 1, 1992 

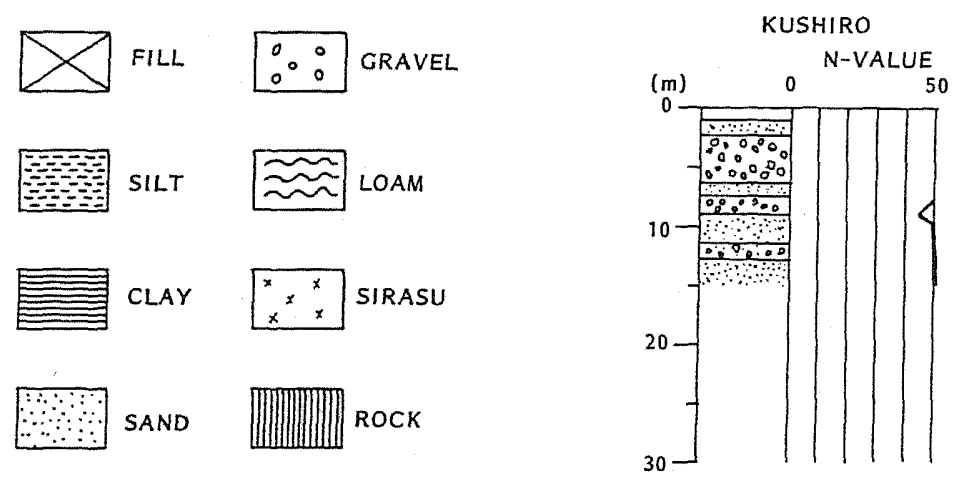

Fig. 19. Soil profile of the Kushiro site.

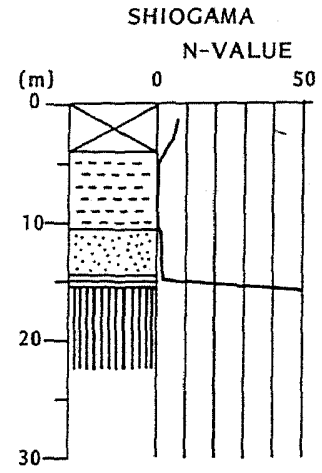

Fig. 20. Soil profile of the Shiogama site.

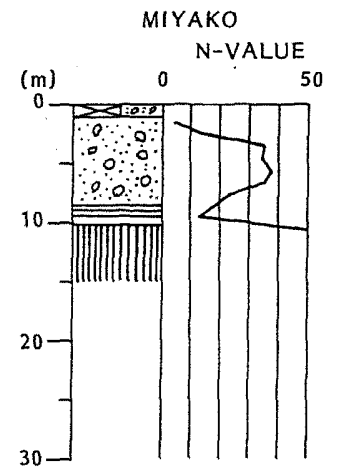

Fig. 21. Soil profile of the Miyako site.

It may be summarized for each site as follows.

\section{I Kushiro site}

One can find less variation of soil amplifications between weak and strong motions for this site. The origin may be due to the firm sand and gravel layers deposited in the depths from 0 to $15 \mathrm{~m}$. As will be mentioned also for the other sites such as Miyako and Tomakomai, it seems that a site principally containing firm sandy gravel in shallow layers less than $10-15 \mathrm{~m}$ deep shows slight variation of amplification factors owing to motion level. Accordingly, it would be emphasized that the non-linear effect of soil amplification is small for this kind of site. This is compatible with the fact that the Hartzell method was successfully applied to the Kushiro site (Kamiyama, 1988). Apart from the above indication, the predominant period around $1.0 \mathrm{~s}$ distinguished in Fig. 11 would be impossible to explain only by the soil profile in Fig. 19. This predominant period may be originated as a resonant period of a surface layer deposited continually from the soils in Fig. 19 overlying on a deep rock space which is hard enough to show a strong contrast against the upper surface layer. 


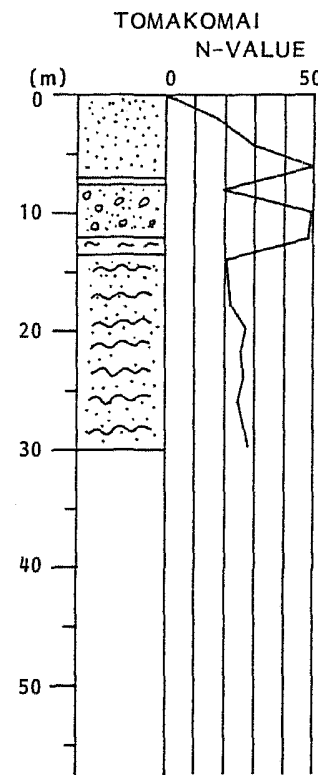

Fig. 22

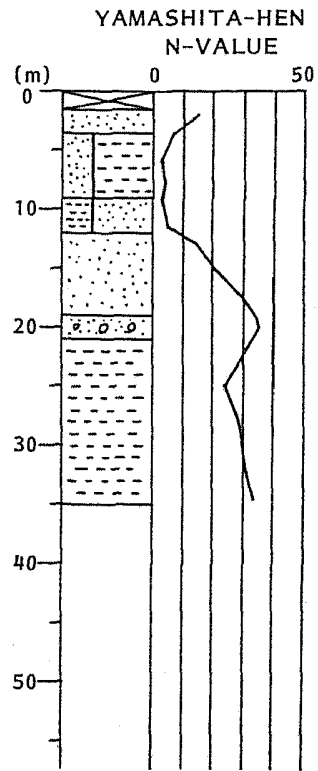

Fig. 23

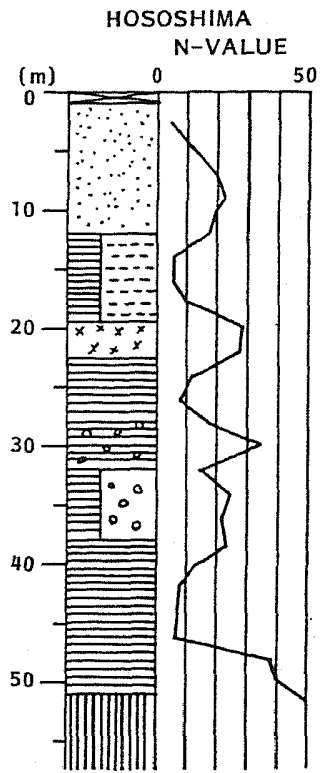

Fig. 24

Fig. 22. Soil profile of the Tomakomai site.

Fig. 23. Soil profile of the Yamashita-hen site.

Fig. 24. Soil profile of the Hososhima site.

\subsection{Shiogama site}

It is clear in Fig. 12 that the predominant periods lengthen and at the same time the amplification, especially for short-periods, decreases as the maximum velocity increases. These phenomena may be closely connected with the extremely soft silty layer on the hard rock. That is, they can be clearly explained by the material non-linearity of the soft silty soil in which the strain-dependent rigidity and damping, respectively, decreases and increases with increasing strain, i.e., with increasing maximum velocity. From this example, one can emphasize that monotonous linear response is not expected but highly non-linear behavior becomes apparent during strong motions at a site of soft surface layers such as Shiogama.

\subsection{Miyako site}

This site has a clear predominant period in relatively short-period region in comparison with the other sites. This can be explained by the presence of the shallowest hard rock layer among all the shown sites. Different from the Shiogama site, this site has a tendency to demonstrate rather larger amplification around the predominant period with the increase of maximum velocity, showing little lengthening of the predominant period. This may be attributable to the stiff gravel layer near the ground surface whose non-linear hysteretic stress-strain relationship differs considerably from that of the soft soils in the Shiogama site. 


\subsection{Tomakomai site}

At this site, similarly to the Kushiro site, the variations of amplification are slight in the periods shorter than about $1.0 \mathrm{~s}$, and on the contrary the amplifications beyond the period become greater with increasing maximum velocity. For instance, a clear predominant period appears at around $2.5 \mathrm{~s}$ in the amplification at a large maximum velocity level of $12 \mathrm{~cm} / \mathrm{s}$. This may be associated with the existence of the underlying low-rigidity layer of loam as well as with a deep rock deposit which is not recognized in Fig. 22. Perhaps the "vibration impedance" between the low-rigidity loam and the supposed rock becomes remarkable in compliance with decreasing rigidity of the loam, and as a result the long predominant period becomes apparant.

\subsection{Yamashita-hen site}

This site shows a similar variation of amplifications to that of the Tomakomai site except for the remarkable decrease of amplifications in short-periods. The short-period behavior may be connected with the rather soft sandy silt layers deposited near the ground surface. Namely, the sandy silt layers whose $N$ values are distributed ranging less than 10 may have a hysteretic characteristics similar to Shiogama's soft silty soils.

\subsection{Hososhima site}

The amplifications of this site vary in a similar way to the Shiogama site. That is, the predominant periods increase and the amplifications in short-periods become smaller in proportion to maximum velocity. This site is composed of several layers which change alternately their softness, but their averaged $N$ value is rather small and this site is regarded, as a whole, as one soft layer on a hard rock deposit. This may be the reason that the Hososhima site is similar to the Shiogama site in the variation of amplifications.

As a result of the above comparisons, it may be concluded that the non-linear soil amplifications of each site correlate intimately with their soil formations and the dynamic material non-linearity has a close relation with the rigidity parameter of the soil materials like $N$ value.

\section{Discussion}

The non-linear soil amplifications obtained here are based solely on a statistical method. Any theoretical and physical techniques of response analysis are not implied in them. This may give rise to two contrary opinions: one is that the results have a persuasive power because they were derived as an integrated form on the main basis of observed records; the other is that the physical validity of the results should be checked by any means because they lack mechanical backgrounds. It is doubtless that the soil amplifications presented here resulted from overall effects peculiar to local site conditions and at the same time they contain some statistical errors. The former opinion is related to the inclusiveness of the overall effects and the latter stems from the statistical errors. In addition to these effects and errors, the results are considered to include also the effects due to the difference of wave types. As is well known, local soil layers respond differently to body waves and surface waves, and therefore the soil amplifications due to both types of waves are expected to differ from each other. Such different 
MIYAKO

\begin{tabular}{|c|c|c|c|}
\hline Thickness $(\mathrm{m})$ & Vs $(\mathrm{m} / \mathrm{sec})$ & Density $\left(\mathrm{Mg} / \mathrm{m}^{3}\right)$ & Q-value \\
\hline 2.2 & 164 & 1.7 & 10 \\
7.5 & 300 & 1.9 & 7 \\
1.9 & 164 & 1.7 & 10 \\
& 800 & 2.0 & 100 \\
\hline
\end{tabular}

HOSOSHIMA

\begin{tabular}{|c|c|c|c|}
\hline Thickness $(\mathrm{m})$ & Vs $(\mathrm{m} / \mathrm{sec})$ & Density $\left(\mathrm{Mg} / \mathrm{m}^{3}\right)$ & Q-value \\
\hline 12.0 & 175 & 1.7 & 15 \\
7.5 & 127 & 1.6 & 20 \\
3.1 & 230 & 1.8 & 10 \\
5.4 & 164 & 1.6 & 20 \\
10.0 & 260 & 1.8 & 10 \\
8.0 & 164 & 1.7 & 20 \\
& 850 & 2.0 & 100 \\
\hline
\end{tabular}

Fig. 25. S-wave, density and $Q$ value profiles of the Miyako and Hososhima sites.

amplifications may be included in the results. It is difficult to check exactly the validity of the results keeping all of these things in mind, and a simplified check is attempted here by theoretically obtaining the physical response of local soil layers with the aid of the so-called multiple reflection of S-wave where shear waves are assumed to propagate vertically through flat soil layers. The S-wave velocity profiles and other data for the Miyako and Hososhima sites were already given by Kamiyama and Yanagisawa (1986) after compiling various materials from existing literature, as shown in Fig. 25. The S-wave velocities $\left(V_{\mathrm{s}}\right)$ and $Q$ values in this figure were inferred from the $N$ values and do not necessarily mean the true values. We estimated, as an example, the frequency response function of the S-wave theory based on the soil data in Fig. 25. Figure 26(a) and (b) compare the theoretical frequency response function due to the soil models in Fig. 25 with the statistical non-linear soil amplification of the Miyako and Hososhima sites. Though the theoretical results were estimated within the linear theory, the comparisons present relatively reasonable agreement between the statistical and the theoretical amplifications as a whole. We can point out from the comparisons that the statistical non-linear soil amplifications obtained here are physically reasonable to some extent. Now that the physical validity has been confirmed in this way even though based on one particular theory, it would be relevant to say that the present statistical method is effective to derive non-linearity of response due to local soil layers and that the results of non-linear soil amplification presented in this study are informative enough to examine a possibility of non-linear response at a site for strong earthquake motions in the future.

\section{Concluding Remarks}

In this paper, an empirical method has been attempted to identify non-linear response of local soil layers using observed strong-motion spectra. The method was based on a regression model of strong-motion spectra in cooperation with the concept of the dummy variable and information on maximum particle velocity at the ground surface. The non-linear soil amplification by the method is presented as the variation 


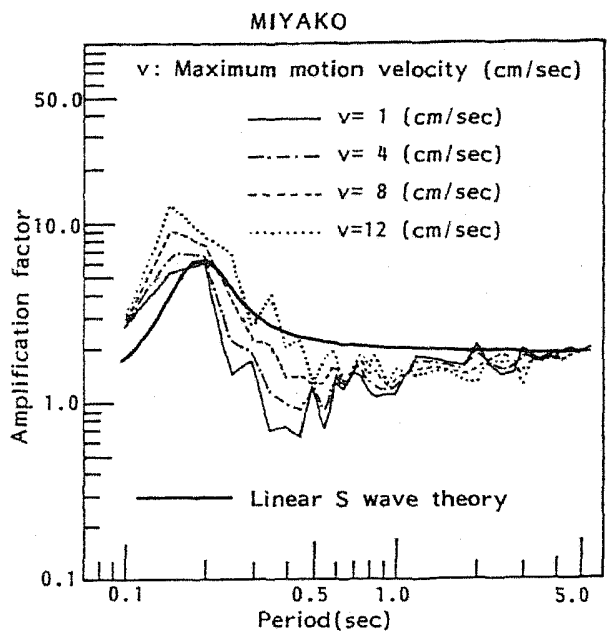

(a)

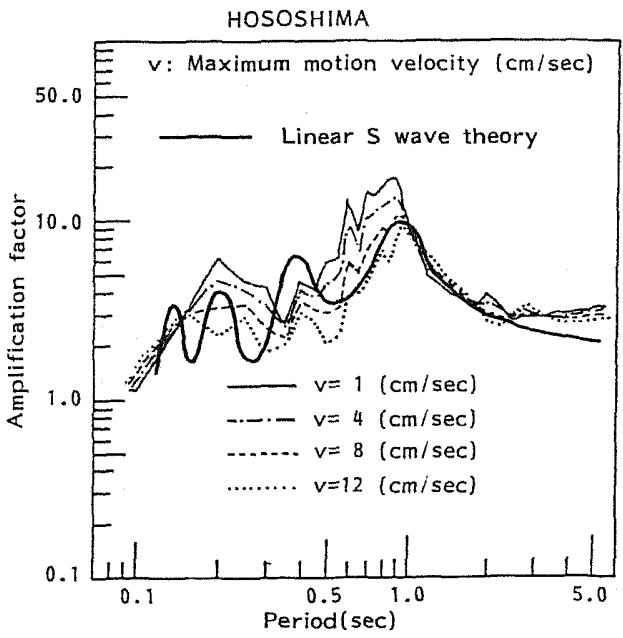

(b)

Fig. 26. (a) Comparison between the statistical non-linear soil amplification and the theoretical amplification due to the S-wave theory for the Miyako site. (b) Comparison between the statistical non-linear soil amplification and the theoretical amplification due to the S-wave theory for the Hososhima site.

of amplification factors with the level of maximum velocity at the ground surface. The non-linear soil amplifications obtained empirically here are quite specific to each observation site, in addition to being dependent remarkably on period. They are also greatly sensitive to the type of soil formations as well as the softness of soils. In particular, the non-linear characteristics of amplification factors are correlated well with $N$ value distribution of soil profile. At a site where there exist soft soils of $10 \mathrm{~m}$ or more in thickness near the ground surface whose $N$ values are distributed with a value less than 10 or 20 , as one example, it is expected that the predominant periods of spectra increase and amplification factors in short-periods decrease together with increasing motion level. In contrast to such a soft soil layer site, a site having surface layers, especially, sandy gravel layers of $5 \mathrm{~m}$ or thicker with an $N$ value greater than about 30 tends not to show clearly detectable non-linearity of soil amplification, and therefore a response analysis based on the linear theory is applicable to this kind of site.

As stated above, the non-linear soil amplification found in the present paper has a close correlation with $N$ value of soils. This suggests that we can obtain strain-dependent rigidity and damping of soil as a function of $N$ value by combining the non-linear soil amplification with some physical response technique. Such an inverse analysis will be presented in a separate paper.

I thank the Port and Harbour Research Institute of the Ministry of Transport of Japan and the Public Works Research Institute of the Ministry of Construction of Japan for providing the strong-motion earthquake records used in this study. I am also greatly indebted to the anonymous reviewers for their thorough reviews on which the paper has been properly revised. This study 
was supported in part by the Grants for Science Research, Project No. 63550342 and No. 02650326 from the Ministry of Education, Science and Culture of Japan. This study was also completed under a Grant-in-Aid for Special Research from the Tohoku Institute of Technology.

\section{REFERENCES}

Aki, K., Local site effects on strong ground motion, in Earthquake Engineering and Soil Dynamics, ed. J. L. Von Thun, Vol. II, pp. 103-155, ASCE, 1988a.

Aki, K., Seismological synthesis of strong ground motion, Proceedings of 9th World Conference on Earthquake Engineering, Vol. III, 9-17, 1988b.

Erdik, M. Ö., Site response analysis, in Strong Ground Motion Seismology, ed. M. Ö. Erdik and M. N. Toksöz, pp. 479-534, D. Reidel Publishing Company, Amsterdam, 1987.

Gazetas, G., P. Dakoulas, and A. Papageogiou, Local-soil and source mechanism effects in the 1986 Kalamata (Greece) earthquake, Earthq. Eng. Struct. Dyn., 19, 431-456, 1990.

Hardin, B. O. and V. P. Drnevich, Shear modulus and damping in soils, J. Soil Mech. Found. Div. $A S C E$, 99, 849-862, 1973.

Hartzell, S. H., Earthquake aftershocks as Green's function, Geophys. Lett., 5, 1-4, 1978.

Iai, S., E. Kurata, and H. Tsuchida, Digitization and correction of strong-motion accelerograms, Technical Note of the Port and Harbour Research Institute, No. 286, 5-56, 1978.

Kamiyama, M., Earthquake source characteristics inferred from the statistically analyzed spectra with aid of dynamic model of faulting, Struct. Eng. Earthq. Eng., 4, No. 2, 391-400, 1987.

Kamiyama, M., A method for predicting strong motion accelerograms by use of small earthquake records, J. Struct. Eng., 34A, 947-959, 1988 (in Japanese with English abstract).

Kamiyama, M. and E. Yanagisawa, A statistical model for estimating response spectra of strong earthquake ground motions with emphasis on local soil conditions, Soil Found., 26, No. 2, 16-32, 1986.

Kanai, K., Relation between the nature of surface layer and the amplitude of earthquake motions, Bull. Earthq. Res. Inst., Univ. Tokyo, 30, 31-50, 1952.

Kolsky, H., Stress Waves in Solids, Dover Publication Inc., New York, 213 pp., 1963.

Okamoto, S., Introduction to Earthquake Engineering, the University of Tokyo Press, Tokyo, pp. 65-96, 1984.

Sánchez-Sesma, F. J., Site effects on strong ground motion, Soil Dyn. Earthq. Eng., 6, 124-132, 1987.

The Port and Harbour Research Institute, Annual report on strong-motion earthquake records in Japanese ports, 1968-1983, Technical Note of the Port and Harbour Research Institute, Ministry of Transport of Japan, No. 98-No. 458, 1969-1983.

Tsuchida, H., E. Kurata, S. Noda, and S. Iai, Site characteristics of strong-motion earthquake stations in ports and harbours in Japan (Part I, II, and III), Technical Note of the Port and Harbour Research Institute, Ministry of Transport, No. 34, 107, 156, 1967, 1970, 1973.

Vol. 40 , No. 1,1992 